\title{
COBERTURA DE LA LENGUA Y CUENTAS BACTERIANAS SALIVARES EN SUJETOS SANOS Y CON GINGIVITIS Y EN PACIENTES CON PERIODONTITIS
}

\author{
'Sergio Mantilla G., "'Monique M. Danser, 'Pali Sipos, "Baherah Rowshani, "Ubele Van der Velden, 'Fridus Van der Weijden. \\ ${ }^{1}$ Odontólogo, U. Santo Tomás. Periodoncista, U. Javeriana. M.SC. Netheriandis institute for Heaith Sciences (NIHES), Erasmus \\ University Rotterdam, Holanda. ${ }^{2}$ Departamento de Periodoncia, Academic Centre for Dentistry Amsterdam, Holanda (ACTA)
}

Autor responsable de correspondencia: Dr: Sergio Mantilla $G$.

e-mail: sergio_mantilla@ustabucaedicco

\section{RESUMEN}

Objetivo: Investigar la coloración y la cobertura de la lengua en sujetos sanos y con gingivitis y en pacientes con periodontitis y determinar la relación entre la apariencia de la lengua y la carga bacteriana en muestras de saliva.

Materiales y Métodos: Se estudiaron dos grupos de pacientes, 70 sujetos sanos y con gingivitis y 56 pacientes con periodontitis. Después de clasificar la lengua se tomó una muestra de saliva de cada paciente; ésta fue analizada usando un microscopio de contraste de fase.

Resultados: Los resultados mostraron que la mayoría de la coloración se encontró en la parte distal de lengua. El número promedio de bacterias por ml de muestra, en relación con una apariencia rosada, blanca y amarilla de la lengua, fue de 948,855 y $900\left(\times 10^{6}\right)$ respectivamente. El numero promedio de bacterias por ml de muestra en relación con no-cobertura, a una cobertura delgada y a una gruesa, fue de 948,863 y $895\left(\mathrm{x} 10^{\circ}\right)$ respectivamente. No se encontró relación entre la coloración, grosor de cobertura y carga bacteriana total. El número promedio de bacterias por ml de muestra en sujetos sanos y con gingivitis fue de 860 y en pacientes con periodontitis, de 918 (x 10\%).

Conclusiones: No se encontró relación entre la apariencia de la lengua y la carga bacteriana salivar. No hubo diferencia en carga bacteriana entre los grupos sanos y con gingivitis y el grupo con periodontitis en la población de estudio. [Mantilla S, Danser MM, Sipos P, Rowshani B, Van der Velden U, Van der Weijden F. Cobertura de la lengua y cuentas bacterianas salivares en sujetos sanos y con gingivitis y en pacientes con periodontitis. Ustasalud 2002;1:7-17]

PALABRAS CLAVES: Cobertura lingual, Recuento bacteriano salivar, Periodontitis.

\section{Tongue Coating And Salivary Bacterial Counts In Healthy Gingivitis Subjects And Periodontitis Patients}

\begin{abstract}
Purpose: The purpose of this study was to investigate the discoloration and coating of the tongue in healthy/gingivitis subjects and periodontitis patients. Furthermore, to determine the relationship between the appearance of the tongue and the bacterial load in salivary samples.

Material and Methods: Two groups of patients were studied, 70 healthy/gingivitis subjects and 56 periodontitis patients. After scoring of the tongue a salivary sample of each patient was taken and analyzed using a phase-contrast microscope.

Results: This investigation showed that most discoloration was found on the distal part of the tongue. The mean number of bacteria per ml sample in relation to a pink, white and yellow appearance of the tongue was 948,855 and 900 $\left(\mathrm{x} 10^{\circ}\right)$ respectively. The mean number of bacteria per ml sample in relation to no, thin, and thick coating was 948,863 and $895\left(\times 10^{\circ}\right)$ respectively. Analysis did not reveal a relationship between discoloration, coating thickness and total bacterial load. The mean number of bacteria per $\mathrm{ml}$ in healthy/gingivitis subjects was 860 and in periodontitis patients $918\left(\times 10^{6}\right)$.

Conclusion: No relationship between the appearance of the tongue and salivary bacterial load could be detected. There was no difference in bacterial load between the healthy/gingivitis and the periodontitis group within the present study population.
\end{abstract}

KEY WORDS: Tongue coating, Salivary bacterial counts, Periodontitis. 


\section{INTRODUCCIÓN}

La estructura papilar del dorso de la lengua forma un sitio ecológico de gran superficie que favorece la acumulación de restos orales y de microorganismos ${ }^{(1,2)}$. Estos microorganismos de la lengua pueden ser de influencia sobre la flora de toda la cavidad oral ${ }^{(1)}$.

Los resultados de un estudio reciente mostraron que la terapia periodontal convencional reduce las proporciones de bacterias periodontales en la bolsa periodontal ${ }^{(3)}$. Sin embargo, no se encontró reducción simultánea en proporciones de estas bacterias sobre las membranas mucosas. Por esto surgió la pregunta si la terapia periodontal debería ser limitada al periodonto, 0 si las membranas mucosas, como la lengua, deberían ser involucradas también en el tratamiento ${ }^{(3)}$.

Varias especies han sido recuperadas en muestras tomadas de la lengua, $P$. Gingivalis ${ }^{(4)}, A$. Actinomycetemcomitans ${ }^{(5.6)}$, E. Corrodens, Capnocytophaga ${ }^{(7)} \mathrm{y}$ Espiroquetas (4). Van der Velden y col. (1986) encontraron que la presencia de organismos móviles y Bacteroides de pigmento negro sobre las superficies mucosas de la lengua y de las amígdalas estaba correlacionado con la presencia de estos mircroorganismos en la placa dental de 23 días ${ }^{(8)}$. Se concluyó que en particular, la mucosa de la lengua y las amígdalas pueden albergar microorganismos periodontopáticos que pueden, posiblemente, actuar como un nido para estas bacterias. Varios estudios han indicado que hay una relación entre los microorganismos presentes en la lengua y los presentes en la saliva ${ }^{(9-11)}$. Un estudio reciente indica que las muestras tomadas de la saliva son un buen medio para detectar microorganismos, tales como $P$ Gingivalis, $P$. Intermedia y $T$. Denticola, en la cavidad oral ${ }^{(12)}$.

La apariencia normal del dorso de la lengua es rosada o tiene una cobertura blanca delgada ${ }^{(13)}$. Esta cobertura de la lengua tiene bacterias, células epiteliales descamadas y liberadas de la mucosa oral, leucocitos de las bolsas periodontales, metabolitos de la sangre y diferentes nutrientes ${ }^{(14-16)}$. Los adultos mayores son más propensos a tener una cobertura en la lengua debido al cambio de dieta, inhabilidad de realizar métodos de higiene oral, disminución en el flujo salivar ${ }^{(17.18)}$. Además, hay un incremento de las papilas filiformes ${ }^{(14)}$. El estado periodontal del paciente parece ser un factor relacionado con el grosor de la cobertura de la lengua. Los sujetos con enfermedad periodontal son más propensos a tener una cobertura más gruesa, comparados con los sujetos con tejidos periodontales sanos ${ }^{(15.16)}$.

En la literatura, hasta la fecha, no se ha encontrado un método bien descrito para analizar el grado de cobertura de la lengua. No hay un índice definido disponible, aunque Miyazaki y col. (1995) presentaron un método de clasificación, dividiendo el dorso de la lengua en tres secciones y clasificando la presencia o ausencia de cobertura de la lengua ${ }^{(20)}$. Sin embargo, no se incluyó análisis de coloración o grosor de la cobertura. Por esto, en este estudio se desarrolló una modificación de este método, con el fin de describir la apariencia del dorso de la lengua en relación con la extensión del color y grosor de la cobertura de la lengua.

Los objetivos del presente estudio fueron, basados en el nuevo índice, investigar la prevalencia de la cobertura de la lengua en sujetos sanos y con gingivitis y en pacientes con periodontitis. Además, determinar la relación entre cobertura de la lengua y carga bacteriana en muestras salivares en estas dos poblaciones.

\section{MATERIALES Y MÉTODOS}

\section{Sujetos}

La población de estudio constó de dos grupos de pacientes. Un grupo de 70 participantes, que eran los sujetos sanos o con gingivitis que asistian al chequeo semestral en la policlínica de ACTA (Academic Centre for Dentistry Amsterdam). Los criterios de inclusión fueron:

1. DPSI 0, 1, 20 3- (Índice de Rastreo Periodontal Holandés, que es una modificación del índice CPITN (21,22)) (Tabla 1). 2. Edad mayor de 18 años.

3. No tener prótesis total.

El segundo grupo consistió de 56 pacientes remitidos al Departamento de Periodoncia de ACTA para tratamiento periodontal. Los criterios de inclusión fueron:

1. DPSI $3+04$ (Tabla $1^{(21,22)}$ ).

2. Edad mayor de 18 años.

\section{Cuestionario}

Los voluntarios contestaron un cuestionario con preguntas acerca de la edad; hábitos alimenticios; hábitos de bebidas (café, té o vino tinto); consumo de cigarrillos (número de cigarrillos por día); hábitos de higiene oral, salud general y halitosis. 
Tabla 1. DPSI (Índice de Rastreo Periodontal Holandés) (Anónimo, 1999): Se divide la boca en seis sextantes. Se tiene en cuenta el mayor puntaje del sextante. Debe haber minimo dos dientes en cada sextante, en el caso en que sólo haya un diente, ésteserá contodo en el sextante adyacente.

\begin{tabular}{|c|c|}
\hline Puntaje & Caracteristicas \\
\hline 0 & $\begin{array}{l}\text { Bolsas con profundidad menor a } 3 \mathrm{~mm} \\
\text { No sangrado al sondaje } \\
\text { No presencia de cálculos y/o restauraciones desbordantes }\end{array}$ \\
\hline 1 & Los mismos criterios que en el puntaje 0 pero con sangrado al sondaje \\
\hline 2 & Los mismos criterios que el puntaje 1 pero con cálculos y/o restauraciones desbordantes. \\
\hline 3 & $\begin{array}{l}\text { Bolsas de } 4-5 \mathrm{~mm} \\
\text { Sangrado al sondaje } \\
\text { Cálculos supra y subgingivales y/o restauraciones desbordantes } \\
\text { Sin recesion }\end{array}$ \\
\hline $3+$ & Los mismos criterios que para el puntaje 3- pero con recesión \\
\hline 4 & Bolsas mayores a $6 \mathrm{~mm}$ \\
\hline
\end{tabular}

\section{Coloración y cobertura de la lengua}

En cada paciente se clasificó el dorso de la lengua para la coloración y cobertura de acuerdo con el método que se describe más adelante. Luego se tomaron dos diapositivas de las lenguas de los pacientes, usando el mismo tipo de película y el mismo tipo de lente. Las diapositivas debian mostrar desde la punta a las papilas de la lengua.

\section{Análisis de la coloración y cobertura}

El procedimiento para analizar la cobertura fue una modificación del método descrito por Miyazaki y col. (1995) y sugerido por Winkel (2000) ${ }^{[23]}$. Se dividió la lengua en 9 partes: Desde las papilas a la punta, tercio posterior, tercio medio y tercio frontal (de acuerdo a Miyazaki y col.

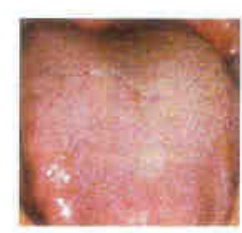

1

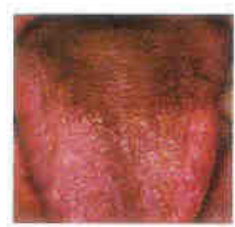

3

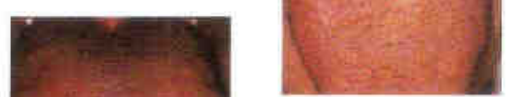

2

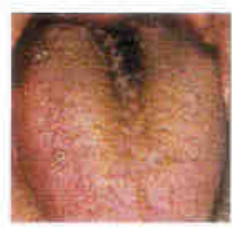

4
1995). Además, desde la izquierda a la derecha, tercio izquierdo, tercio medio y tercio derecho. Para cada una de las nueve secciones, la coloración y la cobertura fueron analizadas visualmente. La coloración fue clasificada en una escala de 0 a 4 ( 0 = Rosada, 1 = Blanca, $2=$ Amarillo/Marrón Claro, $3=$ Marrón y $4=$ Negro) (Figura 1) y la cobertura se clasifico, de acuerdo con el grosor, en una escala de 0 a $2(0=$ Sin cobertura, $1=$ Delgada y $2=$ Gruesa) (Figura 2). La cobertura delgada se clasificó cuando el color rosado subyacente se podía ver a través de la cobertura. La cobertura gruesa - pesada se clasificó si no se podía ver el color rosado bajo la cobertura. Cada sección de la lengua debería ser cubierta en más de un tercio para obtener una clasificación diferente a 0 . Además, se registró la presencia o ausencia de fisuras.

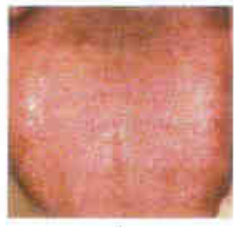

1

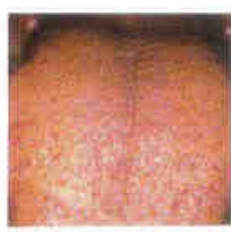

1

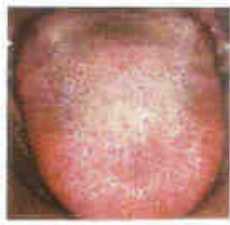

2

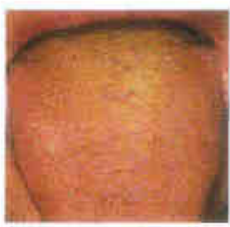

2 
Acuerdo del análisis de la cobertura de la lengua

Para desarrollar un método de entrenamiento de los examinadores en para clasificar la extensión, coloración y grosor de la cobertura de la lengua se evaluó si las diapositivas clínicas podían ser usadas para este propósito. Para determinar el acuerdo entre el análisis usando diapositivas y el análisis clínico, las diapositivas fueron proyectadas en una pantalla y el examinador (SMG) clasificó las diapositivas usando el mismo método y criterios como los usados durante el análisis clínico. Para evitar el sesgo del recuerdo del examinador las diapositivas se observaron en forma aleatoria.

Para analizar el acuerdo dentro del examinador y entre examinadores, dos examinadores (PMS y BR) participaron en un ejercicio de estandarización y entrenamiento por el primer examinador (SMG). Subsecuentemente se clasificaron todas las diapositivas usando los mismos métodos y criterios como los usados durante el análisis y las clasificaron, una nueva vez, una semana después. En esta segunda sesión las diapositivas fueron proyectadas en forma aleatoria para evitar el sesgo del recuerdo de los examinadores.

\section{Microbiología}

Se les pidió a los pacientes que se enjuagaran con $10 \mathrm{ml}$ de solución salina estéril $(0,85 \% \mathrm{NaCl})$ por 20 sgs, después expectoraron en un vial (Adaptado de Ramberg y col. 1994) ${ }^{(24)}$. Posteriormente este vial fue colocado en un vórtex por 20 sgs. En total 100 ul de esta solución fueron pipeteados en un tubo de ensayo y 100 ul de RTF a concentración doble fueron adicionados a esta solución para obtener una concentración de RTF descrita por Syed y Loesche ${ }^{(25)}$. Adicional a lo anterior, se le colocaron 20 ul de extracto de Fildes como lo sugirió Petit y col. (1991) (26). Este tubo de ensayo se colocó en el vórtex de nuevo por 20 segundos. Antes del análisis la muestra se revolvió aspirando la suspensión 5 veces a través de una jeringa de tuberculina (Jeringa Terumo de $1 \mathrm{ml}$ con una aguja neolus $0,45 \times 12 \mathrm{~mm}$ ) y se colocó en el vórtex nuevamente por 20 segundos, para dar una muestra homogénea. Se colocó una gota de la suspensión en una cámara de conteo de Thoma con cuadrados que cubren $1 / 400 \mathrm{~mm}^{2}$. En cada análisis un mínimo de 100 bacterias se contaron en cuadrados escogidos al azar. Usando el microscopio de contraste de fase se contó el número total de bacterias. Estas se diferenciaron en cocos, bacilos,microorganismos móviles y espi-roquetas, como lo describieron Listgarten y Helldén ${ }^{(23)}$.
También fue registrado el número de cuadros requeridos para contar 100 bacterias, con el fin de calcular el número de microorganismos por $\mathrm{ml}$ de muestra.

\section{Análisis estadístico}

Se analizó la clasificación de coloración y grosor de la cobertura para cada una de las 9 secciones de la lengua. Para cada sección se calculó la distribución del porcentaje de las clasificaciones en la población de estudio. Cada sujeto se clasificó según la categoría más alta de coloración y grosor de la cobertura de la lengua en una o más de las 9 secciones. Para cada sujeto el número de secciones que mostraba la clasificación más alta fue determinada y se calculó el promedio. Para el análisis microbiológico el número total de bacterias por ml de la muestra se calculó de la siguiente manera: El número de bacterias fue dividido por el número de cuadros que habían sido necesarios para alcanzar aproximadamente 100 microorganismos, lo que representa el número promedio de bacterias por cuadro. Los cuadros de la cámara Thoma son $1 / 400 \mathrm{~mm}^{2}$ en superficie y $0,02 \mathrm{~mm}$ en profundidad. Por lo tanto el número promedio de bacterias por cuadro fue multiplicado por $20 \times 10^{6}$ para obtener el número de bacterias por ml de la suspensión. Como compensación para la dilución con RTF y el extracto de Fildes este número fue multiplicado por 2,2 para obtener el número de bacterias por ml de la muestra. También se determinaron porcentajes de cocos, bacilos, microorganismos móviles y espiroquetas. Se usaron pruebas no-paramétricas de Mann-Whitney para probar diferencias entre los grupos. "La apariencia normal de la lengua" fue caracterizada por ser rosada o con una cobertura blanca delgada, como criterio de clasificación en cada sujeto ${ }^{(13)}$. "La apariencia de la lengua con cobertura" fue caracterizada por una coloración blanca gruesa o una coloración de amarilla a negra, con una cobertura delgada o gruesa. Se realizó un análisis estadístico dividiendo la población en "apariencia normal de la lengua" y en "apariencia de la lengua con cobertura". Se usaron pruebas de chi-cuadrado para probar la hipótesis de que había diferencias en la apariencia de la lengua entre el grupo sano y con gingivitis y el grupo con periodontitis. También se realizó un análisis de regresión logística, en el que la variable dependiente fue la apariencia de la lengua (normal o con cobertura). Las variables independientes fueron: Edad (en años); estado periodontal; género; hábito de bebida de café, té o vino; estado de salud general; consumo de dulces, especias; hábito de fumar; uso de clorhexidina 0 listerine; seda dental, cepillo interdental palillos y núme- 


\section{RESULTADOS}

ro diario de cepillado dental; halitosis; presencia de fisuras y porcentajes de cocos, bacilos, microorganismos móviles y espiroquetas. Para el análisis del acuerdo en el método para describir la apariencia de la lengua se calcularon los porcentajes de acuerdo entre los diferentes análisis y diferentes examinadores. Se establecieron valores $\mathrm{p}<0.05$ como estadísticamente significativos y se utilizó SPSS para el análisis estadístico.

\section{Población de estudio}

La Tabla 2 muestra una descripción general de la población de estudio. La edad promedio fue de 41 años con un rango de 19 - 71 años. El $51 \%$ de la población era de género femenino. Había más fumadores en el grupo de pacientes con periodontitis que en el grupo sano y con gingivitis. El género y edad fueron distribuidos en forma equitativa en ambos grupos.

Tabla 2. Descripción de la población de estudio.

\begin{tabular}{c|c|c|c}
\hline \multicolumn{2}{c|}{ Sanos/gingivitis } & neriodontitis & Total \\
\hline VARIABLE & $\mathrm{n}: 70$ & 46 & $\mathrm{n}: 126$ \\
\hline Edad promedio (DE) & $40(11)$ & $25-71$ & $19-71$ \\
\hline Rango de edad & $19-70$ & $28(50 \%)$ & $65(51 \%)$ \\
\hline Número de mujeres(\%) & $37(53 \%)$ & $30(53 \%) \diamond$ & $48(38 \%)$ \\
\hline Número de fumadores(\%) & $18(26 \%)$ & & $410)$ \\
\hline
\end{tabular}

$\diamond \mathrm{p}=0.001$ (Test de Mann-Whitnney)

\section{Apariencia de la lengua}

La distribución geográfica de la prevalencia de coloración del dorso de la lengua muestra que la mayoría de la coloración se encontró en los 2/3 distales, donde la parte media muestra una prevalencia más alta de cobertura amarilla (46\%). El análisis estadístico en relación con la coloración mostró que el número de tazas de café estaba altamente asociado con la coloración amarilla $(\mathrm{OR}=1,20$, $\mathrm{p} \leq 0.05)$.

Al igual que la coloración, la mayoría de cobertura de la lengua se encuentra en la parte distal, en el tercio medio del dorso de la lengua.

Posteriormente se dividió la población de estudio en "apariencia normal de la lengua" y en "apariencia de la lengua con cobertura", basados en la combinación del resultado de coloración y cobertura (ver análisis estadístico).
Los resultados muestran que, entre los pacientes con periodontitis prevalecía una apariencia con cobertura de la lengua ( $59 \%$ versus $43 \%$ ) (Chi-cuadrado $\mathrm{p}=0.07$ ). Un análisis posterior mostró que la edad fue un factor significativo en relación con la prevalencia en la cobertura de la lengua $(O R=1.05, p \leq 0.05)$. La Tabla 3 muestra el análisis del grosor de la cobertura en relación con las diferentes categorías de edad. Estos resultados indican un incremento en la clasificación 2 (cobertura gruesa) después de la edad de 40 años, comparado con los grupos de menor edad.

\section{Carga bacteriana}

La Figura 3 muestra la relación entre la coloración y la carga bacteriana salivar en cada paciente. El número promedio de bacterias por $\mathrm{ml}$ en relación con una apariencia rosada (color 0) fue de $948 \times 10^{6}$. Para una aparien- 
Tabla 3. Porcentaje de sujetos por grupo de edad de acuerdo con el grosor de la cobertura (puntaje $0=$ Ninguna, puntaje $1=$ Delgada y puntaje $2=$ Gruesa).

\begin{tabular}{l|c|c|c}
\hline \multicolumn{4}{c}{ Cobertura } \\
\hline Grupo de edad & 0 & 1 & $\mathbf{2}$ \\
\hline $19-29(n=22)$ & 14 & 45 & 41 \\
\hline $30-39(n=30)$ & 10 & 47 & 43 \\
\hline $40-49(n=49)$ & 6 & 33 & 61 \\
\hline $50-59(n=20)$ & 5 & 40 & 55 \\
\hline $60-71 \quad(n=5)$ & 0 & 40 & 60 \\
\hline
\end{tabular}

cia blanca (color 1) y amarilla (color 2), el número promedio de bacterias fue $855 \times 10^{6}$ y $900 \times 10^{6}$, respectivamente. Se detectó una relación entre la coloración y la carga bacteriana total. Se encontró una diferencia cualitativa, en donde el número de bacilos por ml fue menor en sujetos con una cobertura blanca comparado con los que no tenían coloración $(\mathrm{p}=0.004)$ o una coloración amarilla ( $\mathrm{p}=0.007$ ).El número de bacterias en las muestras salivares, según la cobertura, se muestra en la Figura 4. El número promedio de bacterias por $\mathrm{ml}$ con coberturas 0,1 y 2 fue de $948 \times 10^{6}, 863 \times 10^{6} \mathrm{y}$ $895 \times 10^{6}$, respectivamente. No se detectó una relación entre el grosor de la cobertura y la carga bacteriana total. Un análisis posterior demostró una diferencia cualitativa en donde el número de bacilos por ml fue menor en sujetos con una cobertura delgada comparado con los que no tenían cobertura $(p=0.01)$. El número total de bacterias por $\mathrm{ml}$ entre "apariencia normal de la lengua" y "apariencia de la lengua con cobertura" fue similar (891 x $10^{6}$ versus $\left.881 \times 10^{6}\right)$. El número de microorganismos móviles fue menor en los pacientes con apariencia de la lengua con cobetura comparado con los pacientes que presentaban una cobertura normal $(p=0.03)$.
Figura 3, carga bacteriana en relación con la coloración de la lengua en las muestras tomadas de salive

Coloración 0 (rasada) $\mathrm{n}=10$, coloración 1 (blanca) $\mathrm{n}=49$, coloración 2 (amarilla) $\mathrm{n}=67$

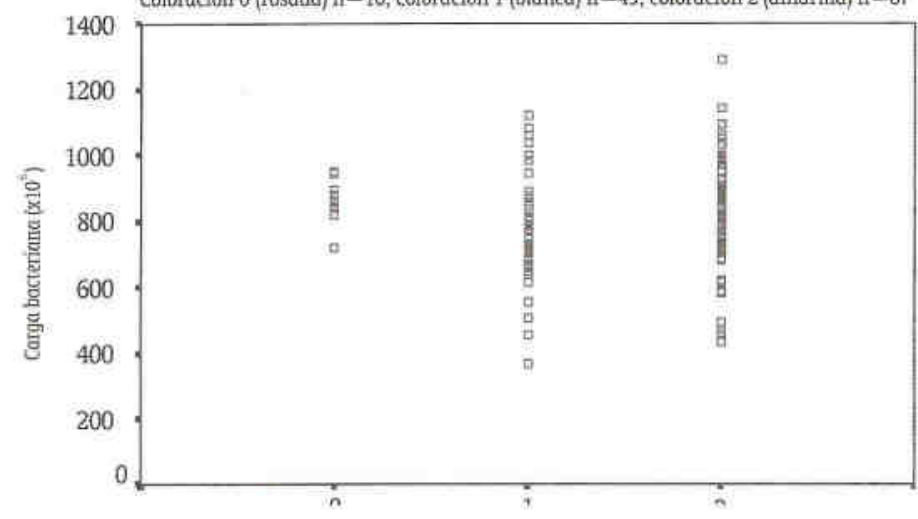

Figura 4, Carga bacteriana en reloción con el grosor de la cobertura en muestras tomadas de saliva

Cobertura $0($ sin cobertura) $n=10$, cobertura 1 (deigada) $n=50$, cobertura 2 (gruesa) $n=66$

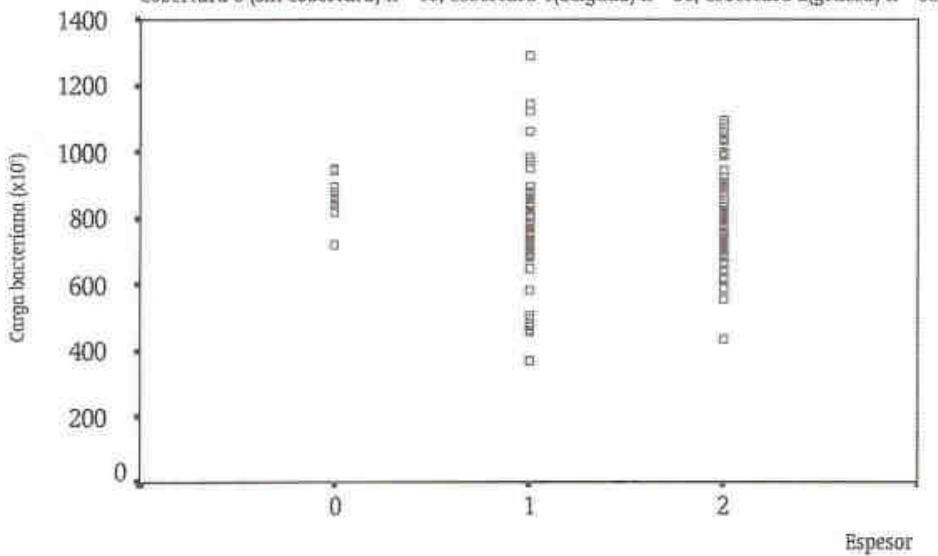


Sujetos sanos y con gingivitis y pacientes con periodontitis

La Tabla 4 muestra los datos microbiológicos divididos en sujetos sanos y con gingivitis y pacientes con periodontitis. El número promedio de bacterias por $\mathrm{ml}$ fue $886 \times 10^{6}$. No se encontraron diferencias entre los dos grupos de pacientes.
Los cocos formaron proporcionalmente la principal parte de la flora salivar, seguido por bacilos los cuales representaron el $8 \%$. Los microorganismos móviles representaron $1 \%$ y las espiroquetas el $0.5 \%$. Aunque la diferencia fue pequeña, la presencia de espiroquetas así como de los bacilos fue mayor en los pacientes con periodontitis (Prueba de Mann-Whitnney $\mathrm{p}<0.0001$ ).

Tabla 4. Carga bacteriana en muestras tomadas de saliva en relación con el estada de salud periodontal.

\begin{tabular}{|c|c|c|c|}
\hline & Sanos/gingivitis & Periodontitis & Total \\
\hline \multicolumn{4}{|c|}{ Nủmero promedio de microorganismos $\times 10^{6}$ por ml (DE) } \\
\hline Total & $860(181)$ & $918(148)$ & $886(169)$ \\
\hline Cocos & 793 (159) & $803(120)$ & $797(142)$ \\
\hline Bacilos & $56(37)$ & $95(44) 0$ & $73(45)$ \\
\hline Móviles & $9,5(14)$ & $13(30)$ & $11(23)$ \\
\hline Espiroquetas & $2,1(5)$ & $8,1(11) 0$ & $4,8(9)$ \\
\hline \multicolumn{4}{|c|}{ Porcentaje promedio de flora (DE) } \\
\hline Cocos & $92(4)$ & $88(6)$ & $90(6)$ \\
\hline Bacilos & $6(3)$ & $10(4) 0$ & $8(4)$ \\
\hline Móviles & $1(1)$ & $1(3)$ & $1(2)$ \\
\hline Espiroquetos & $0,2(0,6)$ & $0,9(1) \diamond$ & $0,5(1)$ \\
\hline
\end{tabular}

op $<0.0001$ (Test de Mann-Whitnney)

La Tabla 5 muestra la prevalencia de la cobertura de la lengua y la coloración en sujetos sanos y con gingivitis y en pacientes con periodontitis. Los resultados muestran que la apariencia rosada de la lengua (color 0) no fue un hallazgo común. En esta población la coloración más alta fue la amarilla (color 2). No se observaron colores 3 ó 4. Una apariencia blanca (color 1) se encontró en el $39 \%$ de la población y una apariencia amarilla en el $53 \%$. El área de la lengua con una apariencia blanca fue mayor en los pacientes con periodontitis comparado, con los sujetos

Tabla 5. Apariencia del dorso de la lengua en relación con el estado de salud periodontal.

\begin{tabular}{|c|c|c|c|}
\hline & Sanos/gingivitis & Periodontitis & Total \\
\hline APARIENCIA & $\mathrm{n}: 70$ & ㄱ: 56 & 126 \\
\hline \multicolumn{4}{|l|}{ Coloración } \\
\hline $0=$ Sin coloración & $6 \%$ & $11 \%$ & $8 \%$ \\
\hline $1=$ Color Blanco & $40 \%[2,9]$ & $37 \%[4.9] \bullet$ & $39 \% 6[3.7]$ \\
\hline $2=$ Color Amarillo & $54 \%[4.1]$ & $52 \%[3.7]$ & $53 \%[3.7]$ \\
\hline \multicolumn{4}{|l|}{ Cobertura (grosor) ${ }^{*}$} \\
\hline $0=\operatorname{Sin}$ cobertura & $6 \%$ & $11 \%$ & $8 \%$ \\
\hline $1=$ Cobertura delgada & $46 \%[3.4]$ & $32 \%[3.4]$ & $40 \%[3.4]$ \\
\hline $2=$ Cobertura gruesa & $48 \%[2.7]$ & $57 \%[3.3]$ & $52 \%[2.9]$ \\
\hline \multicolumn{4}{|l|}{ Apariencia } \\
\hline Normal & $57 \%$ & $41 \%$ & $50 \%$ \\
\hline Con cobertura & $43 \%$ & $59 \%$ & $50 \%$ \\
\hline
\end{tabular}

"Una o más de las nueve secciones muestran esta caracterísica como el puntoje más alto para el total de la superficie de la lengua.

[] número promedio de secciones de la lengua con este resultado en la población del estudio $\diamond \mathrm{p}=0.001$ (Test de Mann-Whitnney) 
sanos y con gingivitis (número promedio de secciones 4.9 versus 2.9) ( $p=0.001$ ) (Figura 5). La cobertura blanca en pacientes con periodontitis se encuentra en forma más frecuente en los 2/3 distales de la lengua, mientras que en los sujetos sanos y con gingivitis el tercio distal fue más frecuentemente cubierto por una cobertura blanca. El porcentaje de sujetos sin una cobertura fue también bajo (8\%). Una cobertura delgada se observó en $40 \%$ de los pacientes y una cobertura gruesa en el $52 \%$.

Figura 5. Porcentaje de sujetos por sección de la lengua con cobertura blanca

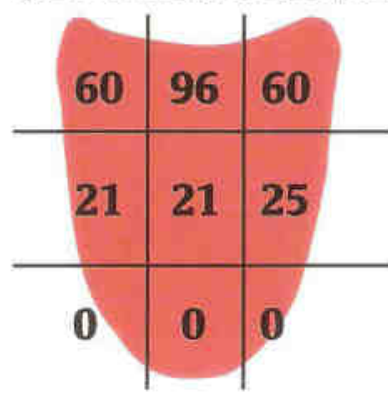

Sanos / Gingivitis

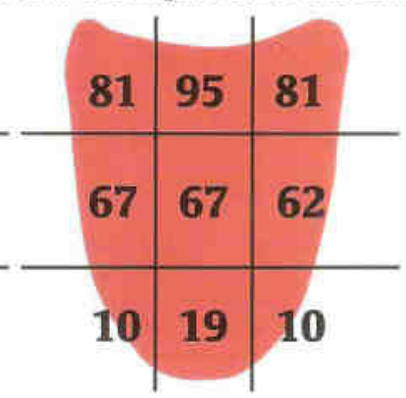

Periodontitis

\section{Fisuras y cobertura de la lengua}

La presencia de fisuras en la población de estudio fue del $27 \%$. No hubo diferencias en la carga bacteriana entre los sujetos con y sin fisuras. Tampoco la presencia o ausencia de la cobertura fue relacionada con las fisuras.

\section{Análisis clínico (in vivo) versus análisis con diapositivas}

Para el análisis del acuerdo entre la clasificación clínica y la clasificación con diapositivas, se utilizaron 103 diapositivas. 23 diapositivas fueron rechazadas para eva- luación posterior, ya que estos pacientes no fueron capaces de sacar la lengua suficientemente para tomar la diapositiva, para un análisis adecuado de la superficie de la lengua desde la punta a las papilas posteriores. Por esto no sería posible clasificar el dorso de la lengua completamente en esas diapositivas. El porcentaje de acuerdo más alto (92\%) se obtuvo en el tercio frontal de la lengua. El porcentaje más bajo fue $60 \%$, que se obtuvo en el tercio medio para cobertura y el tercio posterior para coloración (61\%). En promedio hubo un acuerdo de $73 \%$ en las 9 secciones.

Los resultados para el porcentaje de acuerdo entre y dentro de los examinadores se observan en la Tabla 6 . El porcentaje de acuerdo dentro de los examinadores para coloración y cobertura fue comparable para cada examinador. En promedio, se obtuvo aproximadamente un acuerdo del $70 \%$ entre los dos análisis con una semana de diferencia (Figura 6). El porcentaje de acuerdo entre los exa-

Figura 6. Porcentaje de acuerdo para la cobertura y la coloración por sección de la lengua
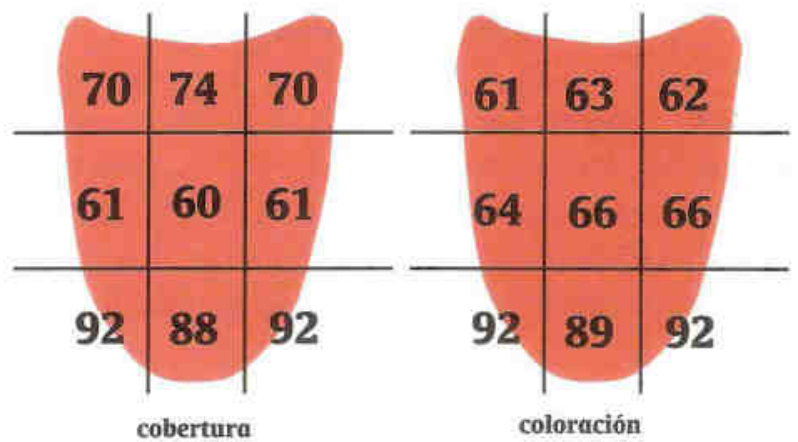

coloración

Tabla 6. Porcentaje de acuerdo entre los diferentes análisis de apariencia del dorso de la lengua intra y entre los examinadores.

\begin{tabular}{l|c|c}
\hline \multicolumn{1}{c|}{ Coloración } & Intra-examinadores & Entre-examinadores \\
\hline Examinador 1 & $62 \%$ & \\
\hline Examinador 2 & $76 \%$ & \\
\hline Análisis 1 & & $56 \%$ \\
\hline Análisis 2 & & $43 \%$ \\
\hline Promedio & $69 \%$ & $50 \%$ \\
\hline \multicolumn{1}{c|}{ Cobertura } & Intra-examinadores & Entre-examinadores \\
\hline Examinador 1 & $63 \%$ & \\
\hline Examinador 2 & $77 \%$ & $64 \%$ \\
\hline Análisis 1 & & $51 \%$ \\
\hline Análisis 2 & & $58 \%$ \\
\hline Promedio & $70 \%$ & \\
\hline
\end{tabular}


minadores para el análisis de coloración fue menor comparado con el grosor de la cobertura. En promedio un acuerdo del $50 \%$ se encontró para coloración y $58 \%$ para el grosor de la cobertura.

\section{DISCUSIÓN}

A pesar del hecho de que la lengua ocupa $1 / 3$ de la cavidad oral parece pasar desapercibida para la mayoría de los odontólogos. En las últimas décadas la lengua ha sido olvidada debido a la necesidad de concentrarse en la protección y tratamiento de los tejidos dentales duros y sus estructuras de soporte ${ }^{(28)}$.

Se considera que la apariencia normal de la lengua tiene una capa delgada de una cobertura blanca ${ }^{(13)}$. Este tipo de cobertura está conformado por ramas cornificadas, restos epiteliales, saliva, bacterias, partículas alimenticias, así como células blancas de exudado. El examen citológico de la cobertura normal de la lengua raramente muestra leucocitos, lo cual sugiere que no existe inflamación visible de la lengua. El pH del ambiente de la cavidad oral con una cobertura rosada o blanca es neutro. Se ha encontrado que el $\mathrm{pH}$ de la cavidad oral con otras apariencias de la lengua es alcalino o ácido ${ }^{(14)}$. Se han utilizado varios métodos para analizar la presencia de la cobertura de la lengua. Yaegaki \& Sanada (1992b) describen un método para medir la cobertura de la lengua en donde la cobertura fue removida cuidadosamente con un raspador de lengua y se estimó el peso húmedo de ésta ${ }^{(16)}$. Gross y col. (1975) usaron un índice de 0 a 3, es decir sin cobertura hasta una cobertura severa; sin embargo, no se mostró ni la descripción clínica ni las fotografias para visualizar tal índice ${ }^{(29)}$. Bosy y col. (1994) estimaron la cantidad de cobertura sobre la superficie dorsal de la lengua por examen visual como pesada, mediana, liviana y sin cobertura ${ }^{(2)}$. Miyazaki y col. (1995) analizaron el estado de la cobertura de la lengua de acuerdo con el área de distribución así: $0=$ no visible; $1=$ menos de un tercio del dorso de la lengua cubierto; $2=$ menos de dos tercios y $3=$ más de dos tercios ${ }^{(20)}$. Chen clasificó la cobertura de la lengua por el color (blanco, amarillo, gris y negro) y por la calidad de la lengua (seca resbaladiza, seca y rugosa, espinosa, parcialmente fisurada y totalmente fisurada) (13). Se han propuesto varios métodos para analizar la cobertura de la lengua, pero ninguno de ellos da un método exacto para clasificarla. Para el análisis de la lengua en este estudio, se realizó una modificación del método descrito por Miyazaki y col. (1995), el cual también describe la coloración, grosor y extensión de la cobertura ${ }^{(20)}$. Los resultados mostraron que la mayor acumulación de cobertura está localizado en la parte posterior, especialmente en la sección media de la lengua, que raramente está libre de cobertura. Este hallazgo está de acuerdo con Christensen (1998), quien sugiere que la sección de la lengua con más restos y acumulaciónes alimenticias es la parte posterior de la lengua. Como consecuencia, si se lleva a cabo la limpieza de la lengua, uno se debe enfocar en la región más posterior de la lengua ${ }^{(30)}$. El color no se relacionó con la carga bacteriana. Sin embargo, se encontró una relación entre la apariencia amarilla y el consumo de café.

En este estudio la apariencia de la lengua fue dicotomizada en "apariencia normal" y "apariencia de la lengua con cobertura". Se observó una tendencia entre los pacientes con periodontitis a tener una mayor prevalencia de "apariencia de lengua con cobertura", comparado con los sujetos sanos y con gingivitis. Un análisis posterior estableció que esta diferencia puede ser debida al hecho de que la extensión de superficie de lengua cubierta por una cobertura blanca es mayor entre los pacientes con periodontitis. Este hallazgo está de acuerdo con el estudio de Yaegaki \& Sanada (1992b), quienes calcularon el peso húmedo de la cobertura de la lengua que pudo ser removida ${ }^{(16)}$. Ellos también encontraron una capa considerablemente más gruesa de la cobertura de la lengua en los pacientes con periodontitis.

Al realizar un análisis de regresión logística en el que la variable dependiente fue la apariencia de la lengua (normal o con cobertura), se encontró que la edad incrementa la probabilidad de la presencia de una cobertura de la lengua ${ }^{(17,18)}$. Así mismo, en un estudio de 5.403 sujetos se encontró que la proporción de sujetos con una lengua rosada o una cobertura blanca delgada, lo cual se considera como apariencia normal de la lengua, disminuye con la edad ${ }^{(19)}$.

En este estudio, se utilizaron muestras de saliva para analizar la carga bacteriana en la cavidad oral. Se ha sugerido que las muestras de saliva son un buen indicador de las bacterias presentes en la lengua ${ }^{(9)}$. Existe una relación entre la presencia de microorganismos en la lengua y en la saliva ${ }^{(11)}$. Los resultados del presente estudio no mostraron diferencias en la carga bacteriana en pacientes con apariencia normal de la lengua comparados con apariencia de la lengua con cobertura; tampoco se encontraron diferencias con la presencia o ausencia de 
fisuras sobre la lengua. El promedio de cuentas bacterianas en este estudio fue de $886 \times 10^{6}$ por $\mathrm{ml}$ de la muestra, los cuales son diferentes de los resultados encontrados por Ramberg y col. (1994). La razón para este desacuerdo puede ser que Ramberg y col. (1994), hasta donde se puede interpretar, no compensaron por la dilución de la muestra con el medio de transporte ${ }^{(24)}$. Por otra parte ellos usaron un cultivo microbiológico, método con el cual no es posible detectar todos los microorganismos presentes en la muestra.

Aunque los resultados de las muestras salivares no revelaron diferencias en la carga bacteriana total entre los grupos sanos y con gingivitis y el grupo con periodontitis, sí hubo diferencias cualitativas. El número de bacilos y espiroquetas fue mayor en el grupo con periodontitis comparado con los sujetos sanos y con gingivitis. Aunque el porcentaje de espiroquetas del 0,5 al $1 \%$ fue bajo, este porcentaje está de acuerdo con los resultados de Petit y col. (1994), quienes encontraron $0,5 \%$ de espiroquetas en la saliva de pacientes con periodontitis ${ }^{(31)}$. Timmerman y col. (1998), en un grupo de sujetos no tratados, no encontraron diferencias en prevalencias de espiroquetas en muestras tomadas de saliva en sujetos con pérdida de inserción, al compararlos con los de la misma comunidad pero sin pérdida de inserción ${ }^{(6)}$. Ellos estudiaron una población que nunca ha visitado al odontólogo para tratamiento dental y que casi nunca usan métodos de higiene oral. En el presente estudio la población visitaba regularmente al odontólogo y estaba acostumbrado al cepillado dental.

Quirynen y col. (1998) estudiaron la diferencia en carga microbiana, usando muestras tomadas de lenguas de pacientes con presencia de cobertura de la lengua comparado con ausencia de esta cobertura y la presencia de fisuras comparado con lenguas suaves ${ }^{(14)}$. Al igual que en el presente estudio no encontraron diferencias en la carga bacteriana total en relación con la presencia o ausencia de cobertura. Por el contrario de De Boever \& Loesche (1995) encontraron diferencias significativas en UFC totales en muestras tomadas de la lengua en pacientes con lenguas fisuradas comparado con pacientes con lenguas lisas ${ }^{(32)}$. Ellos también encontraron diferencias en UFC totales en pacientes con presencia de cobertura de lengua al compararlo con pacientes sin cobertura de lengua. Sin embargo, en ese estudio la población de estudio fue pequeña $(n=16)$.
En conclusión el método que fue desarrollado para el presente estudio para analizar la apariencia de la lengua indicó que la mayoría de coloración y cobertura está localizada en la parte posterior especialmente en la sección media. Se encontró una relación entre la edad y la presencia de una apariencia con cobertura. Además, en el grupo de pacientes con periodontitis la extensión de una cobertura blanca sobre el dorso de la lengua es mayor. No se encontró relación entre la presencia de cobertura y la carga bacteriana salivar. Parece no haber diferencia en la carga bacteriana entre el grupo sano y con gingivitis y el grupo con periodontitis en la población de este estudio.

\section{BIBLIOGRAFÍA}

1. Jacobson SE, Crawford JJ, McFall WR. Oral physiotherapy of the tongue and palate: relationship to plaque control. I Am Dent Assoc $1973 ; 87: 134-139$.

2. Bosy A, Kulkarni GV, Rosenberg M, McCulloch CAG. Relationship of oral malodor to periodontitis: Evidence of Independence in discrete subpopulations. J Periodontol 1994; 65: 37 - 46.

3. Danser MM, Timmerman M, Van Winkelhoff AJ, De Graaf J, Van der Velden $U$. The effect of periodontal treatment on periodontal pathogens on the oral mucous membranes. J Periodontol 1996; 67: 478 - 485 .

4. Lee KH, Tamer ACR, Maiden MFJ, Weber HP. Pre-and post-implantation microbiota of the tongue, teeth, and newly-placed implants. J Clin Periodontol 1999; 26: 822 - 832.

5. Asikainen S, Alaluusua S, Saxén L. Recovery of Actinobacillus actinomycetemcomitans from teeth, tongue and saliva. J Periodontol 1991; 62: $203-206$.

6. Timmerman MF, Van der Weijden GA, Armand S, Abbas F, Winkel EG, Van Winkelhoff AJ, Van der Velden U. Untreated periodontal disease in Indonesian adolescents. Clinical and microbiological baseline data. J Clin Periodontol 1998; 25: 215 - 224.

7.Könönen E, Asikainen S, Alaluusua S, Könönen M, Summanen P, Kanervo A, Jousimies-Somer $\mathrm{H}$. Are certain oral pathogens part of normal oral flora in denture-wearing edentulous subjects? Oral Microbiology and Immunology 1991; 6: 119- 122.

8. Van der Velden U, Van Winckelhoff AJ, Abbas F, De Graaf J. The habitat of periodontopatic micro-organisms. J Clin Periodontol 1986; 13; $243-248$.

9. Krasse B. The proportional distribution of Streptococcus salivarius and other streptococci in various parts of the mouth. Odontologisk Revy 1954; 5: $203-211$. 
10. Togelius J, Kristofferson K, Anderson H, Bratthall D. Streptococcus mutans in saliva: intraindividual variations and relation to the number of colonized sites. Acta Odontologica Scandinavica 1984; 42: 157-163.

11. Lindquist B, Emilson CG, Wennerholm $\mathrm{K}$. Relationship between mutans streptococci in saliva and their colonization of the tooth surfaces. Oral Microbiology and Immunology 1989; 4: 71 - 76.

12. Umeda M, Contreras .A, Chen C, Bakker I, Slots J. The utility of whole saliva to detect the oral presence of periodontopathic bacteria. J Periodontol 1998; 69: $828-833$.

13. Chen ZL. Brief history of tongue inspection. Chinese Medical Journal 1987; $100: 38-44$.

14. Quirynen M, Mongardini C, Van Steenberghe D. The effect of a 1stage full-mouth disinfection on oral malodor and microbial colonization of the tongue in periodontitis patients. A pilot study. J Periodontol 1998; 69: 374 - 382.

15. Yaegaki K, Sanada K Biochemical and clinical factors influencing oral malodor in periodontal patients. J Periodontol 1992; 63: 783 - 789.

16. Yaegaki $\mathrm{K}$, Sanada $\mathrm{K}$. Volatile sulfur compounds in mouth air from clinically healthy subjects and patients with periodontal disease. Journal of Periodontal Research 1992; 27: 233 - 238.

17. Ralph WJ. Hygiene of the tongue. Gerodontics 1987: $3: 169-170$.

18. Massier M. Geriatric Dentistry: root caries in the elderly. J Prosthet Dent 1980; 44: 147 - 149 .

19. Chen $\mathrm{ZL}, \mathrm{Hu} \mathrm{QF}$. Recent development in research on tongue inspection. Chinese Medical journal 1986; 99: 444 - 456.

20. Miyazaki H, Sakao S, Katoh Y, Takehara T. Correlation between volatile sulphur compounds and certain oral health measurements in the general population. J Periodontol 1995; 66: 679-684.

21. Anonimo CPITN wordt DPSI. Nederlandse Tandartsenblad 1999; 54: $521-525$.

22. Van Rossum G, Zeegers G. Application of a modified CPITN by dentists in the Netherlands. J Dent Res 1999; 78: 169 (Abstract \# 505).

23. Winkel EG. Comunicación personal, 2000.

24. Ramberg P, Lindhe J, Dahlén G, Volpe AR. The influence of gingival inflammation on de novo plaque formation. J Clin Periodontol 1994; 21: $51-56$.

25. Syed SA, Loesche WJ. Survival of human dental plaque flora in various transport media. Applied Microbiology 1972; 24: 638-644.

26. Petit MDA, Van der Velden U, Van Winkelhoff AJ, De Graaf J. Preserving the motility of microorganisms. Oral Microbiology and Immunology 1991; 6: 107-110.

27. Listgarten MA, Helldén L. Relative distribution of bacteria at clinically healthy and periodontally diseased sites in humans. J Clin Periodontol 1978; 5: $115-132$.
28. Ralph WJ. Oral hygiene-Why neglect the tongue? Aust Dent J 1988; 33: $224-225$.

29. Gross A, Barnes GP, Lyon TC. Effects of tongue brushing on tongue coating and dental plaque scores. J Dental Res 1975; 54: 1236 - 1237.

30. Christensen G. Why clean your tongue? J Am Dent Assoc 1998; 129: $1605-1607$.

31. Petit MDA, Van Steenbergen TJ, Timmerman MF, De Graaf J, Van der Velden U. Prevalence of periodontitis and suspected periodontal pathogens in families of adult periodontitis patients. J Clin Periodontol 1994; $21: 76-85$. 